\title{
Desarrollo rural y actores locales. Los interrogantes de una Organización Institucional de Competencia Económica Dinámica en crisis: El caso SanCor en la provincia de Santa
} Fe, Argentina

\author{
Mario Lattuada \\ CONICET-Universidad Abierta Interamericana \\ Juan Mauricio Renold \\ CIUNR-Universidad Nacional de Rosario
}

\section{Resumen}

El estudio de caso de SanCor Cooperativas Unidas Limitada es relevante por varios motivos. El primero, por la importancia económica y social que tiene en el sector lácteo nacional y en las localidades del interior donde radican sus plantas en las tres provincias más importantes de la Argentina: Santa Fe, Córdoba y Buenos Aires. En segundo lugar, constituye un ejemplo de un proceso organizacional evolutivo que atraviesa distintos estadios, nace como cooperativa de segundo grado y, luego de casi un siglo de existencia, se reconvierte en una cooperativa de primer grado, para terminar finalmente enajenando la casi totalidad de sus activos y gerenciamiento a otras empresas del sector. Tercero, su evolución comprueba una hipótesis planteada hace tiempo sobre el resultado de una de las dos opciones posibles de evolución que presentaban los tipos de Organizaciones Institucionales en Mutación en las tipologías cooperativas propuestas por Lattuada y Renold (2004). Finalmente, como actor destacado del desarrollo territorial local y regional que culmina en un escenario de crisis irreversible, y dada la envergadura alcanzada por la organización, el impacto de su desmembramiento, enajenación y cambio de naturaleza cooperativa, deja enseñanzas y abre numerosos interrogantes sobre sus efectos en la cadena de valor láctea y en el desarrollo de las comunidades donde se encuentra inserta.

\section{Palabras clave}

Cooperativas; Lácteos; Crisis; Desarrollo; Territorio

Códigos JEL: J54, Q13, R11, Z13
RURAL DEVELOPMENT AND LOCAL ACTORS. QUESTIONS ABOUT AN INSTITUTIONAL ORGANISATION OF DYNAMIC ECONOMIC COMPETITION IN CRISIS: THE CASE OF SANCOR IN THE PROVINCE OF SANTA FE, ARGENTINA

\section{Abstract}

The case study of SanCor Cooperativas Unidas Limitada is relevant due to several reasons. First of all, SanCor Cooperativas Unidas Limitada has got a big economic and social importance in the national milk production sector as well as in provincial towns located in the three major Argentine provinces: Santa Fe, Córdoba and Buenos Aires. Secondly, it is an example of an evolving organisational process going through different degrees: emerging as a second-degree co-operative society, a century after, it becomes a first-degree co-operative society, and finally, it disposes of almost all of its assets as well as its management to other companies of the dairy sector. Thirdly, its evolution verifies a hyothesis that had been stated long time ago about the results of one of the two possible evolution choices which could be carried out by the types of Everchanging Institutional Organisations, according to the co-operative societies typologies proposed by Lattuada and Renold (2004). Lastly, as a leading actor of territorial development, it ends up with an irreversible crisis scenario. Due to the big size reached by this organisation, the impact of its breakup, its disposal and its change in its cooperative society nature, it teaches us some lessons, and poses numerous questions about its effects on the dairy value chain as well as on the local development of those communities where it is inserted

Keywords

Cooperatives; Dairy products; Crisis; Development; Territory

JEL codes: J54, Q13, R11, Z13

Fecha de recepción del original: 23 de mayo de 2018; versión definitiva: 15 de diciembre de 2019.

Mario Lattuada, CONICET-Universidad Abierta Interamericana, Chacabuco 90, piso 4 , C1069AAB, Ciudad Autónoma de Buenos Aires, Argentina.

E-mail: mjlattuada@gmail.com, ORCID ID: 0000-0001-5038-8478.

Juan Mauricio Renold, CIUNR-Universidad Nacional de Rosario, Entre Ríos 751, Rosario, (2000), Argentina.

E-mail: juanrenold@yahoo.com.ar, ORCID ID: 0000-0002-3842-4779. 

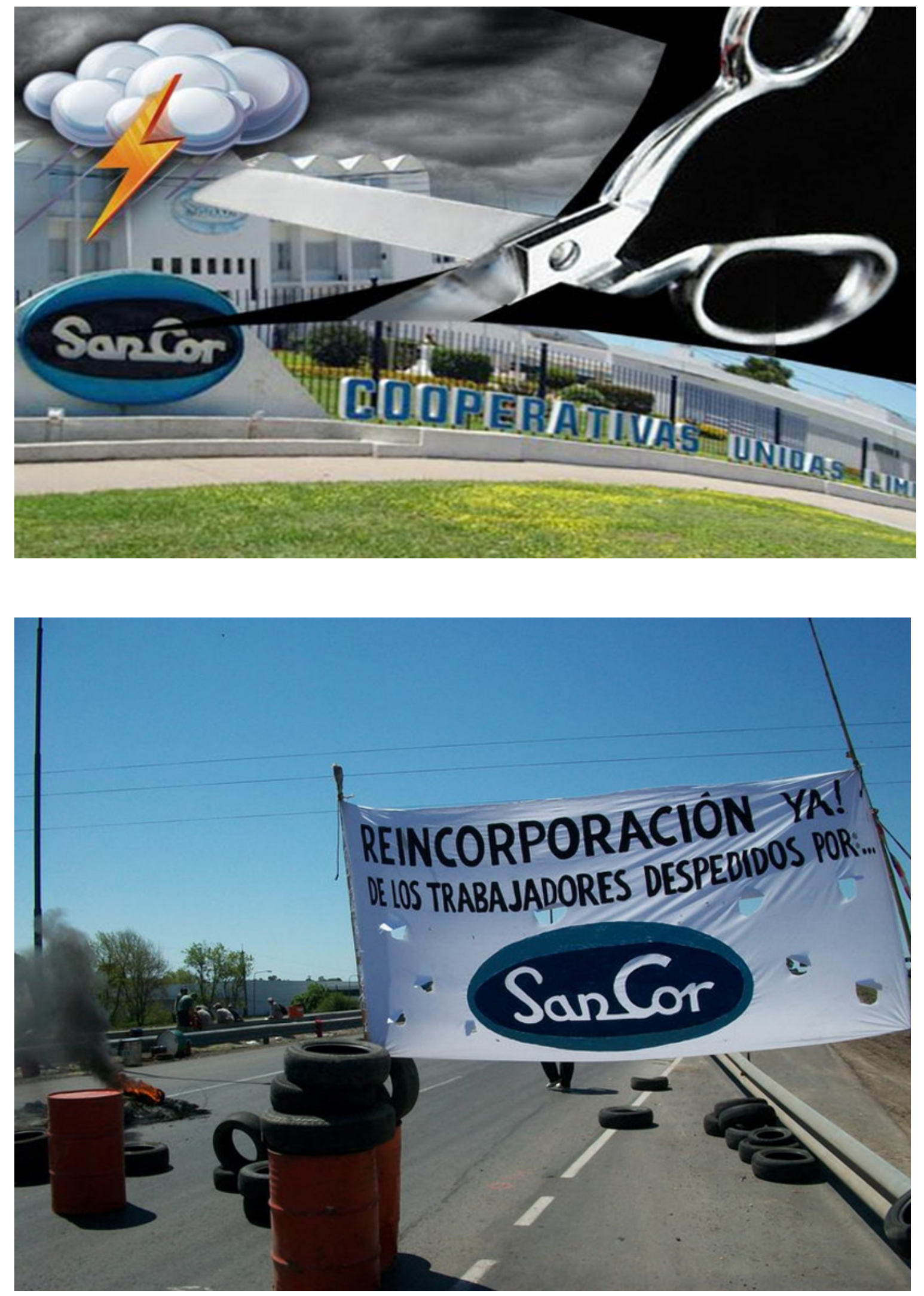


\section{Desarrollo rural y actores locales. Los interrogantes de una Organización Institucional de Competencia Económica Dinámica en crisis: El caso SanCor en la provincia de Santa Fe, Argentina}

Mario Lattuada

CONICET-Universidad Abierta Interamericana

Juan Mauricio Renold

CIUNR-Universidad Nacional de Rosario

1. Introducción

La provincia de Santa Fe es la segunda provincia en importancia de la Argentina por su aporte relativo al Producto Bruto Geográfico (8\%) y al valor total de las exportaciones nacionales $(20 \%)$ compuestas por un $77 \%$ de productos primarios y manufacturas de origen agropecuario.

Esta provincia ha sido históricamente la primera productora de leche de la Argentina. En forma conjunta con la Provincia de Córdoba y Buenos Aires, compone la cuenca lechera más importante de toda Latinoamérica, y SanCorla segunda agroindustria del complejo lácteo.

Los centros de acopio y transformación de las principales cadenas agroalimentarias se distribuyen territorialmente en función de la importancia de la concentración de la producción y la accesibilidad a las vías de comunicación nacional e internacional. Las estructuras más importantes en granos y aceites y la industria frigorífica se asientan en el sur de la provincia privilegiando la ubicación sobre el río Paraná, mientras que la industria láctea lo hace en el centro, oeste y sur de la misma.

En los últimos años, en el marco de los procesos de globalización y su relación con lo local, las variables espaciales asociadas a la localización de la producción, los flujos de comercio y los aspectos sociopolíticos y culturales han sido incorporadas con mayor énfasis en el análisis de los factores condicionantes del desarrollo. Álvarez García y Rendón Acevedo (2010: 58) realizan una observación que compartimos: los territorios no son un factor de competitividad en sí mismos, sino que cuentan con potencialidades que pueden o no ser aprovechadas según las decisiones políticas que se adopten y -agregamos nosotros con el fin de no acotarlo a una cuestión voluntarista- las condiciones técnicas y sociales de organización de la producción que en determinado contexto histórico se constituyen en condiciones de su posibilidad. En consecuencia, los territorios en sus diferentes escalas geográficas de análisis se constituyen en un exponente de las desigualdades sociales y económicas generadas por esos procesos, entre países o conjuntos de países, como también a nivel subnacional, entre regiones, provincias, departamentos, ciudades y unidades de menor dimensión como pueblos y barrios.

A ello se suma, desde otro lugar, que a partir de la década de 1990, se han extendido en América Latina propuestas de desarrollo rural para combatir la pobreza basadas en la articulación de enfoques territoriales e institucionales (Cfr. Schejtman y Ramírez; 2004: 1-2). El paradigma de desarrollo rural propuesto se asienta en el supuesto de una multiplicidad de acciones de tipo económicas o productivas e institucionales específicas promovidas por actores con competencia sobre un territorio, tanto públicos como privados, que cooperan y complementan sus esfuerzos $y$, al que se articulan otros actores de carácter regional o nacional, cuya sumatoria y sinergia confluye en un proceso de desarrollo.

Esta concepción, surgida en un período de la historia en que se pretendía prescindir de la importancia de la intervención del Estado y de las políticas, resulta valiosa por rescatar la importancia del capital social en los procesos de desarrollo local sostenibles en el tiempo.

En este marco, se considera que entre los actores socioeconómicos que potencialmente pueden cumplir un rol relevante como agentes de desarrollo territorial rural merecen destacarse aquellas organizaciones que integran la economía social, especialmente las asociaciones cooperativas que por más de un siglo han constituido un factor de enraizamiento de la economía en el territorio, un factor de desarrollo agrario y un referente social, económico y aún ideológico en las comunidades rurales donde se encuentran asentadas (Moyano Estrada, 2006).

A las transformaciones del sistema económico mundial, deben agregarse otros que son propios de la realidad doméstica. Por una parte el cambio drástico en la orientación de los 
Figura 1. Ubicación de la provincia de Santa Fe en el contexto de Argentina y Sudamérica
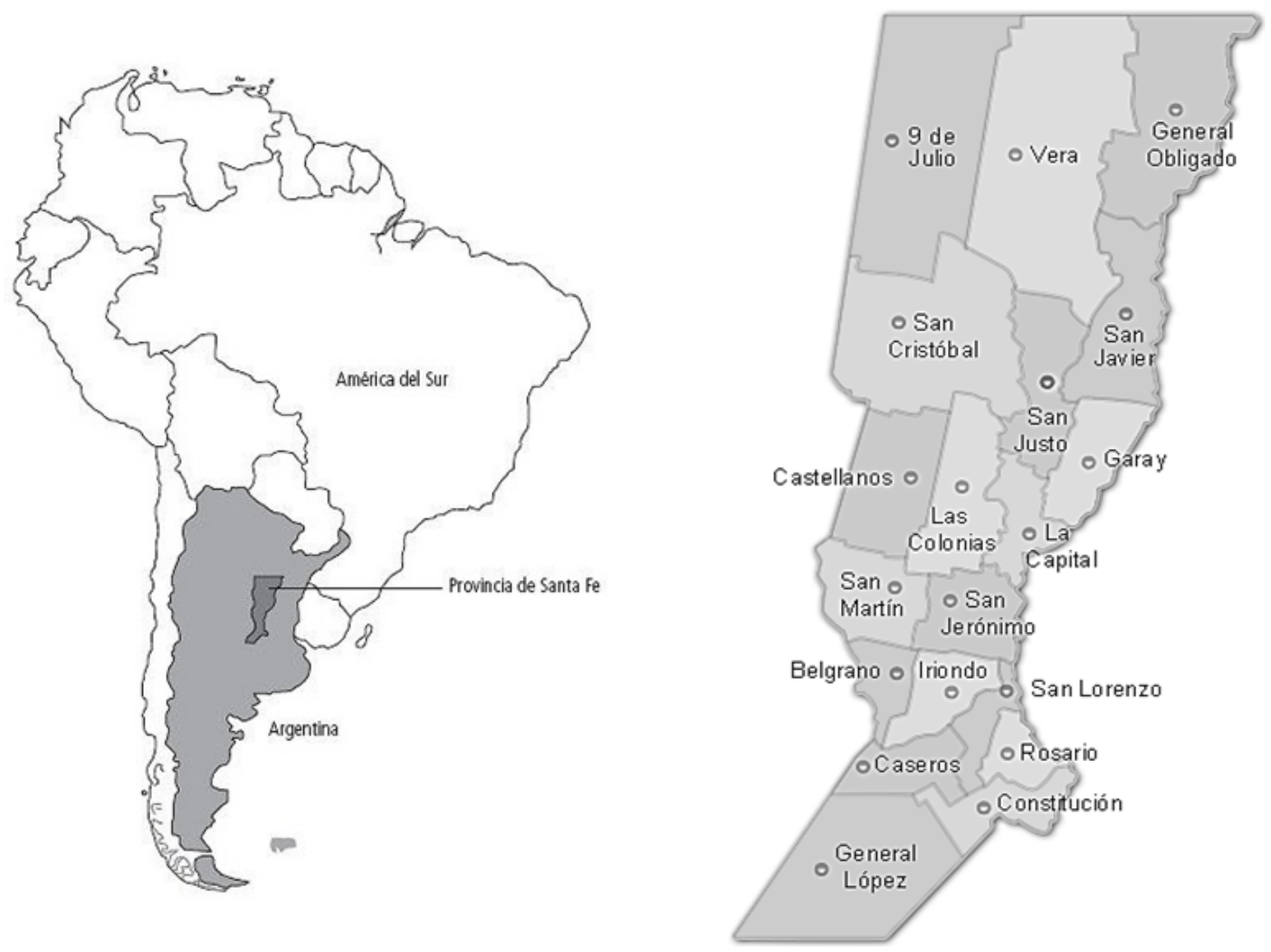

diferentes regímenes sociales de acumulación (Nun, 1987). A ello se agregan, en el plano sectorial argentino, las profundas y aceleradas transformaciones tecnológicas, productivas y organizacionales a partir de redes contractuales complejas en la cooperación de diversos y heterogéneos actores en la producción y articulación de los eslabones de las cadenas agroalimentarias (Bisang et al., 2008; Barsky y Gelman, 2009; Anlló et al., 2010).

Estos procesos de orden macrosocial afectan de modo diferencial a las organizaciones de la economía social dada la diversidad de sus manifestaciones en los diferentes países y la heterogeneidad de su expresión empírica dentro de cada realidad nacional, lo cual exige profundizar el análisis a partir de estudios de casos de tipo instrumental. En este sentido, el caso cumple el rol de mediación para la comprensión de un fenómeno que lo trasciende, con el objeto de evidenciar características de algún fenómeno o teoría, por lo que el foco de la atención y la comprensión desborda los límites del caso en estudio, el cual puede ser interpretado como ejemplo.

En trabajos previos hemos construido una tipología estructural de las instituciones cooperativas caracterizadas y diferenciadas por sus formas de organización y funcionamiento (Renold, 1995; Lattuada y Renold, 2004), delineado un mapa de situación de la realidad del sector cooperativo agrario argentino, con información estadística sobre número de entidades y asociados, actividades y servicios ofrecidos, personal empleado, situación económica y nivel de participación en la comercialización agropecuaria (Lattuada et al., 2011a), y

hemos explorado y destacado la importancia de ciertas asociaciones cooperativas de envergadura en los sectores vitivinícola, agrícola y lácteo de la Argentina en la construcción de capital social para el desarrollo (Lattuada et al., 2011b).

En esta oportunidad articulamos aquellos trabajos para dar contexto a los cambios en los aspectos cualitativos de la mayor organización cooperativa agroindustrial de la Argentina especializada en el rubro lácteo, con ramificaciones en otros sectores de actividad como servicios y seguros, con sede central en la provincia de Santa Fe y complementaria en otras regiones del país, y un ámbito de negocios de orden nacional e internacional.

El caso de SanCor Cooperativas Unidas Limitada, es relevante por varios motivos. El primero, por la importancia económica y social que tiene en el sector lácteo nacional y en las localidades del interior donde radican sus plantas en las tres provincias más importantes de la Argentina: Santa Fe, Córdoba y Buenos Aires. En segundo lugar, constituye un ejemplo de un proceso organizacional evolutivo que atraviesa distintos estadios, nace como cooperativa de segundo grado y, luego de casi un siglo de existencia, se reconvierte en una cooperativa de primer grado, para terminar finalmente enajenando la casi totalidad de sus activos y gerenciamiento a otras empresas del sector. Tercero, su evolución comprueba una hipótesis planteada hace tiempo sobre el resultado de una de las dos opciones posibles de evolución que presentaban los tipos de Organizaciones Institucionales en Mutación en las tipologías cooperativas propuestas por Lattuada y Renold (2004). Final- 
mente, como actor destacado del desarrollo local y regional en la provincia de Santa Fe durante un proceso que fue exitoso durante un largo período histórico, culmina en un escenario de crisis irreversible, y dada la envergadura alcanzada por la organización, el impacto de su desmembramiento, enajenación y cambio de naturaleza cooperativa empresaria, deja enseñanzas y abre numerosos interrogantes sobre sus efectos en la cadena de valor láctea y en el desarrollo local de las comunidades donde se encuentra inserta.

El trabajo fue realizado a partir de una revisión de fuentes primarias y secundarias, históricas y actuales, y se estructura del siguiente modo: en primer lugar presenta una síntesis de la tipología de formas de organización cooperativas haciendo especial referencia a las Organizaciones Institucionales de Competencia Económica Dinámica (OICED), modelo en el que se inscribe el caso de estudio, para luego incursionar en los aportes de las mismas como capital social en el desarrollo del medio rural. A partir de allí ingresamos en el caso SanCor, planteando sus orígenes, las características de la región en la que se inserta y de la cadena de valor láctea y su importancia dominante en la misma, la evolución jurídica y organizativa con especial referencia a las últimas dos décadas en que se define su destino y con él, probablemente, el de comunidades y familias del interior santafesino cuya situación se describe a partir de información periodística reciente. El trabajo concluye con algunas reflexiones de orden cualitativo sobre las enseñanzas de este proceso sobre la evolución del cooperativismo y su rol como capital social.

\section{Las Organizaciones Institucionales de Competencia Econó- mica Dinámica'}

Así como el cooperativismo agropecuario se ha ido transformando en sus aspectos cuantitativos y económicos durante el último siglo, también lo ha hecho en los aspectos ideológicos e institucionales. Las cooperativas agropecuarias surgen en un momento de la historia en el que determinadas condiciones estructurales e ideológicas se articulan o maduran para la generación de una organización social con características que la identifican y diferencian de otras existentes. Las transformaciones de las condiciones originales y de los factores que las constituyen, así como las derivadas de su propia presencia y actuación, van generando tensiones entre los principios doctrinarios y las prácticas cotidianas hasta un punto que desemboca en cambios relevantes de las organizaciones primigenias. Resulta obvio señalar que, de acuerdo con la profundidad de los cambios institucionales que se operen, pueden transformarse sustancialmente los objetivos originales de las mismas.

Este proceso de transformación institucional del cooperativismo agropecuario conduce a formas de organización que

\footnotetext{
${ }^{1}$ El término Organización Institucional de Competencia Económica Dinámica adoptado en este trabajo se inspira en las referencias realizadas a este tipo de organización por Benecke (1973: 188-205).
}

se diferencian sustancialmente unas de otras. Es decir, dentro del cooperativismo encontramos formas organizativas que difieren en las relaciones de sus elementos constituyentes, aunque pueden tratarse como si formaran parte de un gran conjunto o "familia institucional". Si bien todas estas formas de organización cooperativa permiten, en una etapa intermedia, la convivencia de normas y prácticas distintas o incluso contradictorias, se llega a un punto de inflexión donde solo caben dos alternativas de desarrollo institucional: regresar a una situación en la que se dé una mayor coherencia entre las prácticas cooperativas reales y sus normas originales, o modificar drásticamente los principios fundacionales para posibilitar que las cooperativas funcionen como empresas administradoras de capital en sentido estricto.

Desde una perspectiva teórica, y sin que su adopción implique desconocer la heterogeneidad de situaciones empíricas concretas, podemos identificar tres tipos ideales de formas institucionales en la organización cooperativa: organización institucional consecuente (OIC), organización institucional paradojal (OIP) y organización institucional en mutación (OIM). Estos tipos ideales han sido elaborados para expresar la existencia de determinadas relaciones organizacionales de orden interno y su lógica particular, así como para referirse a determinadas actividades específicas de las cooperativas agropecuarias, implicando cierta relación con los contextos cambiantes en los que desarrollan dichas actividades.

A continuación, describiremos brevemente y solo con el objetivo de relacionar tales modelos con las nociones de capital social. En este sentido, se entiende por OIC toda organización donde las fricciones entre las prácticas institucionales y los valores y principios que le dieron origen y orientan sus acciones, se encuentran reducidos a su mínima expresión. Aquí, la racionalidad instrumental orientada a fines se encontraba claramente subordinada a la racionalidad identitaria orientada a valores. Las formas cooperativas en que se expresaba correspondían más a las de un movimiento social, que a las de sociedades u organizaciones formales.

Las causas históricas de la constitución de este tipo de cooperativismo están asociadas a la integración y al compromiso solidario de sus miembros para resolver cuestiones de vulnerabilidad, tanto respecto de las situaciones naturales adversas (climatología), como de las fluctuaciones del mercado en condiciones de monopolio de la tierra, de los costes de los insumos o de las dificultades para la comercialización de los productos.

Este tipo de cooperativas se multiplicó y fortaleció durante la posguerra de mediados del siglo $X X$, evidenciando una fase de crecimiento significativo en la magnitud y diversidad de las operaciones y negocios de las cooperativas, del número de asociados y de unidades de primer grado, y con ello el consecuente desarrollo de una mayor complejidad técnicoadministrativa, así como múltiples instancias de vinculación interinstitucional (cooperativas de segundo grado, confederaciones, etc.).

En esas condiciones, tanto los problemas prioritarios a afrontar, como las motivaciones de sus integrantes y las condiciones para desarrollar sus acciones colectivas, generaron objetivos, intereses y prácticas institucionales distintas a las 
de la etapa anterior de acuerdo con la mayor heterogeneidad interna de sus componentes sociales. Como resultado de ese contexto de cambios, surge el cooperativismo del tipo OIP que fue alejándose de los rasgos identitarios de movimiento social -que identificaban en cierto modo a las primeras cooperativas- para ir convirtiéndose poco a poco en instituciones de naturaleza más instrumental orientadas a cumplir objetivos explícitos y formalizados, mediante un ordenamiento de la conducta de sus miembros y el desarrollo de acciones racionalizadas y programadas, teniendo en cuenta criterios de jerarquía interna, coordinación imperativa y normas de comportamiento de sus miembros. Es decir, las cooperativas del tipo OIP se fueron corporatizando.

En síntesis, las cooperativas del tipo OIP tienen como característica constituyente una permanente tensión institucional para resolver el dilema de la situación de externalidad entre la cooperativa y sus asociados, que no es diferente sustancialmente de una relación entre clientes o de mercado y que denominamos como alteridad burocrática (Lattuada y Renold, 2004). Esta tensión afecta a su esencia e identidad, más allá de los resultados económicamente favorables. En las cooperativas OIP, la primitiva uniformidad social e ideológica es sustituida por una estructura directiva que trata de "resolver, mediante un procedimiento formal y burocrático, la situación (contradictoria y paradójica) de hacer compatible en el seno de la cooperativa, en términos de Max Weber (1984: 20 y ss), simultáneamente, acciones racionales con arreglos a fines (la constitución de una empresa cooperativa donde cuenta el rendimiento económico) y acciones racionales con arreglo a valores (doctrina cooperativista), acciones que en el tipo de cooperativas OIC de la etapa anterior coexistían sin grandes contradicciones -ya que las acciones racionales con arreglo a fines se subordinan a las acciones racionales con arreglo a valores-.

Las OIP poseen una gran complejidad institucional que se traduce en la variación de los criterios y métodos de participación y control. Hay una tendencia a transitar de una representación y control directos y personales -cuando los asociados son reducidos en número y el grado de complejidad de negocios y administrativos escasos- a un tipo de representación delegada-donde los dirigentes reciben instrucciones precisas de sus bases- y finalmente a una forma de representación fiduciaria -en la que los dirigentes tienen una relativa autonomía, a veces muy amplia e incluso completa, para interpretar los "intereses" de sus representados en función de las circunstancias y de los intereses de la propia institución-. Esta delegación fiduciaria se expresará con mayor claridad en el modelo OICED que analizaremos en el próximo punto.

Si bien las OIP pueden permanecer por mucho tiempo sosteniendo esta tensión paradójica sin presentar modificaciones estructurales importantes, ante cambios drásticos en el contexto en el que deben operar, se plantean al menos dos opciones de reformulación institucional en sus potenciales tendencias evolutivas. Una que tienda a recobrar, dentro de los principios tradicionales cooperativos, la revalorización del compromiso societario, los valores solidarios y la participación más o menos directa en una escala institucional y regional que lo haga posible. Y, otra, de orientación más empresarial, que tiende a una reformulación drástica de los principios cooperativos originales, para que se habiliten prácticas más flexibles y cercanas a las empresas de capital y prácticas de mercado. Se trata de Organizaciones Institucionales en Mutación (OIM) que pueden comprenderse desde dos sub-tipos: las mutualistas y las de competencia económica dinámica.

El subtipo mutualista, Organización Mutualista (OM), promueve retomar con mayor vehemencia un acercamiento entre los principios cooperativos y las prácticas institucionales, enfatizando los principios de solidaridad y ayuda mutua, y la participación democrática. Se caracteriza por estrategias que contemplan con mayor intensidad los intereses de los asociados -por ejemplo, a partir de distribución líquida de los beneficios no destinados a las reservas o nuevas inversiones consensuadas-, un desarrollo institucional acotado en su expansión geográfica -local o regional que posibilite la participación directa de los asociados- y reducida complejidad burocrática institucional -reflejada en un número pequeño y eficiente de personal, con escasa diferenciación jerárquica interna, e ingresos acordes a las características socioeconómicas de los asociados-. El cambio de las condiciones de un Régimen Social de Acumulación de apertura y desregulación a un Régimen Social de Acumulación de economía regulada con mayor intervención estatal puede generar, en este sentido, mejores condiciones para el desarrollo y consolidación del subtipo Mutualista.

El segundo subtipo ideal, denominado empresarialnos remite más específicamente a una Organización Institucional de Competencia Económica Dinámica (OICED), ejemplifica con mayor claridad las denominadas Organizaciones Institucionales en Mutación (OIM) en nuestra tipología. Estas OIM tienden a un modelo macro-cooperativo con objetivos de introducir fórmulas de gestión empresarial, en los que prevalecen los criterios de rentabilidad económica en detrimento de los de solidaridad. En estos casos, se busca reducir las diferencias entre las cooperativas y las empresas de capital, con el objetivo de superar las restricciones que le impedirían responder con mayor eficacia a los desafíos del nuevo contexto competitivo. Esto requiere la adopción de una mayor envergadura económica y complejidad institucional, así como expandir su radio de acción a latitudes impensadas para sus asociados, derivadas de las necesidades de escala y grado de integración de las operaciones a abarcar. Implica, también, operar con terceros no asociados, constituir empresas de capital privado, como sociedades anónimas subordinadas para determinadas operaciones, o alianzas estratégicas con empresas privadas de capital independiente. En esta modalidad las acciones racionales con arreglo a valores se subordinan a las acciones racionales con arreglo a fines.

En función de nuestra línea de análisis, el hecho destacado de estas experiencias es que la competitividad y crecimiento en el mercado de las empresas cooperativa mencionadas es una decisión del cuerpo de directores, funcionarios y administradores, en función de la permanencia y crecimiento de la organización que dirigen. Ello implica, a través de mecanismos oligopsónicos de mercado, una subordinación de las decisiones y acciones de las estructuras de primer grado y de los productores que la integran, o en caso contrario el alejamiento de la estructura que ayudaron a crear. 
El discurso de esta Organización Institucional Cooperativa de Economía Dinámica (OICED) se expresa en sentido opuesto e inverso respecto del discurso OIC. Este discurso prioriza en su contenido la eficiencia económica empresarial de la organización y su competitividad en un mercado ampliado, subordinando las referencias a aquellos valores cooperativos que se consideran un obstáculo a la obtención de la misma.

En esta etapa, el cooperativismo agropecuario como sistema se encuentra en un proceso crítico que trasciende las consecuencias cuantitativas, económicas y sociales, e involucra transformaciones de sus estructuras organizativas y principios doctrinales fundacionales. Esta problemática se inscribe en un escenario internacional de transformaciones en el cooperativismo, que se expresa tanto en experiencias concretas, New Generation Cooperatives, como en la revisión y discusión de la doctrina realizada por la Alianza Cooperativa Internacional durante 1995 en Manchester.

\section{La OICED y el capital social}

En relación a lo expuesto hasta aquí, podemos observar las correspondencias entre los tipos morfológicos cooperativos y sus características distintivas, asociados a los niveles e indicadores de capital social propuestos en su modelo por Moyano Estrada (2006)².

a) Desde una perspectiva weberiana sobre las bases de un comportamiento organizacional basado en "valores" o "intereses o fines empresariales", podemos señalar que en el tipo morfológico OIC predomina fuertemente el primero, y tiene una degradación progresiva en beneficio del segundo en los otros modelos, con la excepción del OM donde recupera para sí cierta preponderancia en relación a los intereses.

b) Respecto de la representación y participación de los asociados en la organización se expresa una clara relación inversa entre las formas directas presentes en el modelo OIC y la fiduciaria correspondiente al modelo OICED. En el caso OIP tiene preeminencia la forma delegada con una tendencia hacia la forma fiduciaria mientras que en el modelo OM esta presencia se invierte, otorgándole una importancia creciente a la posibilidad de participación directa.

c) Las posibilidades de ingresar libremente a integrar las cooperativas, expresado en el principio cooperativo de puertas abiertas, tiene limitaciones en algunos de los mo-

\footnotetext{
2 Moyano Estrada (2006) propone abordar el análisis de capital social en el agro a partir de un modelo -con base en una adaptación de los criterios de Woolcock (1998)-, compuesto de dos niveles y cuatro dimensiones. El nivel micro se refiere a los actores individuales y su participación en redes de información y cooperación incluida la cooperativa, mientras que el nivel macro hace referencia a las organizaciones y sus redes de articulación y cooperación. El nivel micro se encuentra compuesto por dos dimensiones: integración intracomunitaria y conexión extracomunitaria mientras que en el nivel macro se despliegan dos dimensiones adicionales: sinergia institucionaly eficiencia organizativa, cada uno de los cuales se expresan en distintos indicadores como puede apreciarse a continuación.
}

delos. Este se cumple en las formas OIC, y también, con ciertas limitaciones en las OIP; mientras que está restringido en las OM y OICED por diferentes motivos. En las primeras para garantizar una mayor participación directa de los asociados en el control, y en las segundas por razones contractuales y asentadas en la eficiencia del negocio (intereses).

d) Los procesos de toma de decisiones internos a las organizaciones cooperativas originalmente se sostenían en el conocido principio democrático de "un hombre, un voto", ampliamente respetado en las OIC y en las OM. Pero de acuerdo a los diferentes tipos morfológicos, este principio se altera parcialmente en las OIP y se transforma radicalmente en las OICED donde la capacidad de decisión se vincula con el grado o volumen de negocio que se opera o concentra.

e) Los ámbitos de acción referidos al modelo OICED, centrados en su proyección nacional y global, contrasta notablemente con los tres tipos morfológicos restantes.

f) Una relación similar se produce en la disposición de recursos económicos y capacidad técnica, con excepción de la OM que a pesar de sus menores dimensiones, sus estrategias de red institucional permite compensar esa menor dimensión de sus recursos.

g) En cuanto a las condiciones de Capital Social a nivel micro, la OIC demuestra un alto grado de integración intracomunitaria y baja integración inter-comunitaria, en forma inversa a la OICED. La OM y en mayor medida la OIP resultan una transición desde el círculo más estrecho de relaciones internas a las vinculaciones con otras organizaciones de la comunidad.

h) En el nivel macro de Capital Social, tanto respecto de la sinergia institucional, como en los niveles de integridad y eficiencia de las organizaciones se expresa una clara tendencia de menor a mayor desde las OIC a las OICED, donde la mayor complejidad organizacional, y de los negocios son determinantes en la cooperación público privada, en las alianzas estratégicas con otras empresas, y en los requerimientos de eficiencia y resultados.

En síntesis, dentro de la economía social se pueden distinguir dos grandes conjuntos de organizaciones, aquellas cuyas bases se encuentran asentadas principalmente en valores y aquellas otras donde predominan los intereses. Las primeras, tienen una alta preponderancia de los factores sociales que contribuyen a los procesos del desarrollo, como la participación directa, la mayor inclusión social, la cohesión, solidaridad, toma de decisiones democráticas, y alto grado de enraizamiento local, y que se identifican con los aspectos micro del capital social como son la integración intra e inter-comunitaria. Este es el caso fundamentalmente de la OIC y OIM Mutualista de nuestro modelo.

Con estos elementos teóricos, por un lado los análisis de corte morfológico y, por otro, respecto de las alternativas a las organizaciones cooperativas en otras formas asociativas y, a la vez, en el capital social que aquellas generan, describiremos a continuación un caso paradigmático. 
Entre los principales actores socioeconómicos con presencia territorial en el centro y noroeste de la provincia de Santa Fe (Argentina), con proyección nacional e internacional que disponen de capacidades o condiciones para constituirse en agentes de desarrollo territorial se encuentra la cooperativa SanCor.

La provincia de Santa Fe, desde los orígenes de la nacionalidad argentina hasta la actualidad, se ha identificado con la producción y exportación agropecuaria: con los granos, la ganadería, y la lechería.

Con la misma intensidad, se ha identificado con una densidad social expresada en una estructura agraria compuesta con participación de numerosos pequeños y medianos productores familiares (arrendatarios y propietarios), muchos de ellos inmigrantes producto de las formas de ocupación del territorio y condiciones sociales de producción generadas a partir de las políticas colonizadoras del siglo XIX; así como con la organización social generada a partir de las colonias, y experiencias institucionales trasplantadas de los acervos culturales europeos como las cooperativas y las sociedades de fomento. Estas características en la constitución del mundo rural provincial, y su importancia en los ejes económicos del desarrollo nacional, han contribuido a la generación de una alta densidad asociativa de los productores rurales de la provincia, expresada en la diversidad y número de organizaciones económicas (cooperativas) y reivindicativas (organizaciones gremiales empresarias) de su historia, y en la trascendencia que algunas de ellas han tenido en el escenario político y económico nacional. Esta provincia históricamente ha sido y continúa siendo la de mayor número de cooperativas agrarias y asociados del país.

\subsection{Los orígenes}

La primera experiencia de cooperativismo lechero en Argentina tiene lugar en la provincia de Santa Fe. En 1918 surgió la Cooperativa de Lechería de Zavalla. El propósito de esta unión, que en ese entonces tenía pocos asociados, era valorizar la materia prima a partir de la elaboración propia de productos, en principio crema.

Las condiciones de los campos de la zona para este tipo de producción junto al crecimiento de la demanda de productos lácteos contribuyeron a la creación de otras cooperativas. Tiempo después, sobre lo que luego se conocería como la "cuenca centro-oeste santafesina", se crearon entre 1925 y 1940 un gran número de asociaciones cooperativas de productores inmigrantes, especialmente suizos, donde los principios cooperativos estaban fuertemente arraigados.
El cooperativismo se consolidó como estrategia para introducir mejoras en los precios de la materia prima y lograr una diversificación productiva. Este objetivo se cristalizó con la creación de una cooperativa de segundo grado que comenzó con una fábrica de manteca en la localidad de Sunchales el 17 de setiembre de 1938 integrada por 18 cooperativas de las provincias de Santa Fe y Córdoba.

\subsection{La región}

La sede central de la cooperativa se encuentra en la localidad de Sunchales, con 17.676 habitantes, perteneciente a la denominada Región 2 de la administración provincial que integran los departamentos: 9 de Julio, San Cristóbal, Castellanos y San Martín.

En su conjunto la región presenta una geografía productiva en la que una buena aptitud en las tierras se combina con polos industriales y de alta tecnología. Se destaca por su gran cuenca láctea, la principal del país, aunque en los últimos años ha sufrido una retracción por la expansión de los cultivos de soja. Además del aporte productivo y de la capacidad de empleo que generan los tambos y toda la cadena de industrialización láctea, la región cuenta con uno de los mayores stocks de ganado bovino de cría de la Argentina. La ciudad de Rafaela lidera la región con la industria de autopartes, metalmecánica y agroalimentaria, mientras que la ciudad de Sunchales, señalada como capital nacional del cooperativismo, constituye un gran polo de industrialización láctea siendo la sede central de SanCor.

La región presenta una infraestructura de comunicaciones heterogénea, caracterizada por la predominancia del transporte automotor y la obsolescencia del sistema ferroviario. La zona norte se distingue por presentar serias deficiencias en los sistemas de abastecimiento de agua potable, y en sus redes de desagües y gas.

Entre las problemáticas que requieren atención, se reconocen la marcada migración desde las zonas rurales a los centros urbanos, la deforestación y la necesidad de un manejo responsable de los suelos. Y ahora, la crisis del sector lácteo cuya máxima expresión es la situación de SanCor.

El Censo Nacional de Población 2010 indica que las ciudades del norte de la región (San Cristóbal, Ceres y Tostado) poseen los indicadores de prestación de servicios básicos más bajos de la provincia (IPEC, 2012).

La ausencia de gasoductos y la insuficiencia de las redes de alta tensión obstaculizan la promoción de estrategias para la radicación de industrias, fundamentalmente en la zona norte. El anegamiento que se produce por efecto de eventos adversos de gran magnitud en períodos de duración cortos (lluvias intensas), los desbordes de ríos y las dificultades de escurrimiento de las aguas producen pérdidas sociales y económicas de gran magnitud debido a la falta de previsión y de obras en las principales cuencas hídricas. 
Figura 2. Provincia de Santa Fe, distribución de tambos

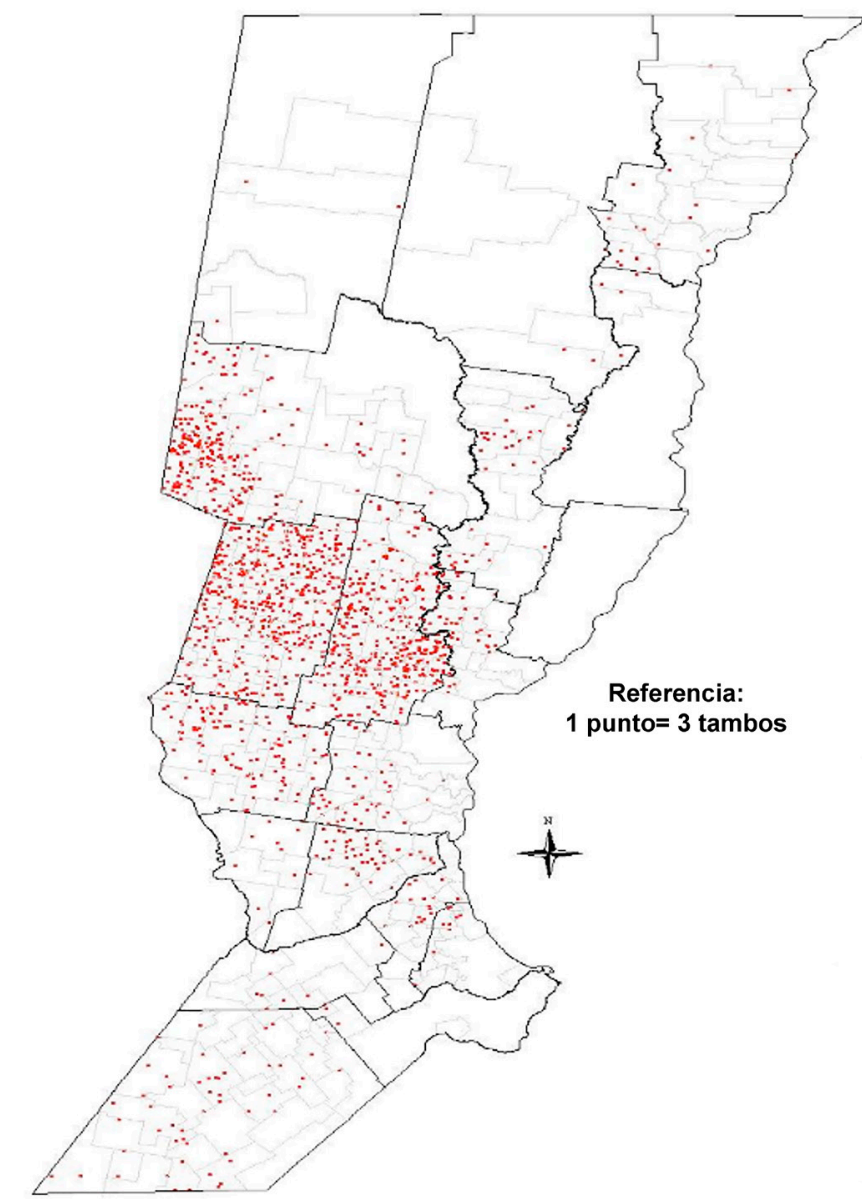

Fuente: Ministerio de la Producción de Santa Fe, Secret. Sist. Agropec., Agroalim. y Biocomb. DGSA-DGPCEF-SI

4.3. La importancia de SanCoren la cadena de valor de la leche

La participación porcentual de la provincia de Santa Fe en las cadenas agroalimentarias del país se expresa en 16 de las 31 cadenas existentes, ocupando alguno de los tres primeros puestos en 12 de ellas, entra las que se encuentra la cadena láctea en la que ocupa el segundo lugar aportando el 33\% del valor agregado total (Anlló et al, 2010).

La provincia de Santa Fe ha sido históricamente la primera productora de leche de la Argentina. En forma conjunta con la Provincia de Córdoba y Buenos Aires, compone la cuenca lechera más importante de toda Latinoamérica, y SanCorla segunda agroindustria más importante del complejo luego de la empresa La Serenísima.

La tendencia histórica demuestra que la cantidad de unidades productivas tamberas fueron disminuyendo en cantidad, mientras que los niveles de producción, salvo fenómenos climatológicos o crisis financieras importantes, se han incre- mentado y se han mantenido la cantidad de animales del rodeo lechero y las hectáreas destinadas a tambo.

Para el año 2007, último registro oficial disponible, la Argentina disponía de 14.000 tambos en actividad con un stock de ganado para leche de 3.800 .000 cabezas, y una producción de 8.571 millones de litros anuales, de los cuales la provincia de Santa Fe disponía del 32\% de los tambos, el 17\% del rodeo para tambo y el $27 \%$ de la producción de leche de todo el país, (Ministerio de la Producción, Gobierno de Santa Fe, 2008).

En la provincia se identifican dos regiones o cuencas lecheras de relevancia. La región centro (o cuenca centro oeste que también comprendería al noreste de la provincia de Córdoba) que aporta el $90 \%$ de la producción y está formada por los departamentos: Castellanos, San Martín, Las Colonias, La Capital, San Jerónimo, San Justo, San Cristóbal, 9 de Julio, Vera y General Obligado. Y la región surque aporta el 9\% de la producción e incluye los departamentos: Belgrano, General López, Iriondo, Caseros, Rosario y San Lorenzo (Nogueira, 2008).

Como puede observarse en la Figura 2, la cuenca del centro oeste de la provincia, sede de SanCor, concentra la mayor cantidad de tambos de la provincia. Los departamentos Caste- 
Ilanos, Iriondo, Las Colonias, La Capital, San Cristóbal, San Justo, San Martín reúnen 4.073 tambos (el 90\% del total).

La leche producida en los tambos santafesinos se entrega diferentes industrias procesadoras entre las cuales SanCor compra los mayores volúmenes producidos. Además, la provincia constituye el área de asentamiento de otras industrias lácteas importantes como Verónica, Milkaut e Ilolay, constituyendo un polo de generación de importantes fuentes de trabajo y actividad económica local y regional (Nogueira, 2008).

SanCor

Para el año 2007, SanCor procesaba anualmente alrededor de 1.400 millones de litros de leche, equivalente al 13,8\% de la producción nacional. Su capacidad industrial y el empleo de 3.954 personas, posibilitaba un procesamiento de $4.000 .000 \mathrm{li}$ tros de leche diarios y la producción de más de 100 variedades de productos y subproductos. Esa capacidad de producción se encontraba distribuida en 16 plantas de diversos tipos: 1 de manteca, 11 para quesos (rallados, procesados, trozados, etc.), 2 para leche refrigerada, 1 para crema, 1 para yogur, postres y flanes, 6 para leche en polvo, 1 para dulce de leche, 2 para leche esterilizada (U.A.T.), 1 para leches especiales y 1 de suero fluido. Además disponía de 2 depósitos de maduración de quesos y 1 planta de fraccionado de leche en polvo.

De acuerdo a la información institucional (www.Sancor. com.ar - consultado 17.12.17), una década después, en 2017 SanCordeclara estar integrada por 520 productores de leche y 55 cooperativas, 3.600 empleados y una capacidad de procesamiento industrial de 4.200.000 litros de leche diarios. Cuenta con 8 plantas operativas: una de leche en polvo, leche U.A.T., leches especiales y dulce de leche en Sunchales (Santa Fe); otra de leche en polvo, manteca y crema en Devoto (Córdoba); cuatro de quesos en Gálvez (Santa Fe), La Carlota (Córdoba), Balnearia (Córdoba) y San Guillermo (Santa Fe); una de quesos y leche en polvo en Mortero (Córdoba); y, finalmente, una de leche U.A.T. y leche refrigerada en Chivilcoy (Buenos Aires).

Según ejercicio 2016-2017 su volumen de producción anual fue de 914.234 .701 litros de leche, con una facturación total de $\$ 10.897 .066 .000$, de los cuales $\$ 8.928 .527 .000(82 \%)$ corresponden al mercado interno y $\$ 1.968 .539 .000$ (18\%) al mercado externo. Teniendo en cuenta estos datos cabe destacar la participación de SanCor en el mercado lácteo nacional, aportando el 27,2\% de la producción de manteca, el 22\% de la producción de quesos untables, el $43 \%$ de quesos rallados, el $20 \%$ de quesos procesados, el $12 \%$ de leches en polvo, el $21,3 \%$ de leches UAT, el $10,7 \%$ de leches refrigeradas, el $24,1 \%$ de leches saborizadas, el $21,9 \%$ de dulce de leche y el $24,6 \%$ de crema de leche.

Los productos de SanCorestán presentes en toda la Argentina y en los cinco continentes, a través de 10 sucursales de ventas, 8 oficinas comerciales, 4 centros de distribución que abastecen a 200 distribuidores exclusivos y más de 140 clientes mayoristas independientes. La cobertura nacional alcanza a 1.800 supermercados y 80.000 comercios minoristas.
Desde hace medio siglo, ha sido constante la presencia de SanCor en las principales plazas mundiales, lo que la ha convertido en el mayor exportador de lácteos de la Argentina. Además de vender sus productos en más de 30 países de los cinco continentes, la cooperativa cuenta con filiales en Brasil, (SanCor do Brasil Produtos Alimentícios), en Estados Unidos (SanCor Dairy Corporation), delegaciones y representantes en México, Perú, Bolivia, Paraguay, y EEUU. Tiene participación societaria en diferentes empresas además de las mencionadas, como AproAgro SA (distribución de insumos agropecuarios), El Hornero SC, Integral Insumos SC, Establecimientos Lácteos San Marco SA y Crear Agropecuaria SC. Además participa de alianzas estratégicas con Arla Foods Ingredientes $S A$ en la elaboración de proteínas lácteas derivadas del suero de queso, Mead Johnson Nutrition en la comercialización de fórmulas infantiles en el cono sur de América, y Arsa (Alimentos Refrigerados Sociedad Anónima) con Vicentin Family Group (un importante holding de empresas agroindustriales del norte santafesino) para la elaboración y comercialización de yogures, flanes y postres.

4.4. Las transformaciones en la organización económica y jurídica

Las drásticas transformaciones del Régimen Social de Acumulación bajo los parámetros del consenso de Washington en la década de 1990 fueron acompañadas por el inicio de una modificación del carácter asociativo de la organización, que comenzó a tornarse más vinculado al éxito empresarial que a los principios cooperativos. En este sentido, SanCorno estuvo ajena al proceso de concentración de la economía que atravesó el país, sino que fue partícipe activo.

Las cooperativas asociadas se redujeron drásticamente. En 1984 había 353 organizaciones asociadas, mientras que poco más de un lustro después solo llegaban a un centenar. Para mediados de la década de 1990, SanCor contaba con 107 cooperativas asociadas, 4.540 productores y un stock ganadero de 300.000 cabezas que producían anualmente 1.700 millones de litros de leche fluida, (Fernández et al., 2004).

Esta disminución en el número de entidades asociadas no se produjo necesariamente por desafiliación o desaparición de las cooperativas, sino que en la gran mayoría de los casos se trató de fusiones de las cooperativas de primer grado a partir de un "... proceso promovido por SanCor con el objeto de hacer más eficiente y competitivo el sistema en su conjunto" (Fernández et al. 2004: 58).

Esta disminución del número de cooperativas y asociados sin embargo no afectó en forma significativa los volúmenes de producción y procesamiento. Entre 1991 y 1999 se produce un período de crecimiento de la producción en base a un fuerte proceso de inversión tecnológica que, en cierto punto, precipitó la posterior desaparición de la actividad de productores pequeños junto a una transformación del patrón productivo. Los requisitos de calidad y cantidad para la materia prima, 
especialmente a nivel del mercado mundial, cuyo ingreso y permanencia interesaba a Argentina, se alcanzaron a través de la incorporación de moderna tecnología, cuyos aranceles de importación se habían reducido al mínimo, razón por la que muchos productores tomaron créditos para poder adquirirlas.

Dada su densidad institucional, SanCor pudo sostener, por un lado, el desarrollo tecnológico requerido por sus cooperativas asociadas. Con este fin, facilitó la incorporación de maquinarias y procesos para la mejora de la calidad del producto a través de la asistencia técnica en el marco de estrategias económicas y de organización empresarial y de instalaciones de equipos de ordeñe y enfriado. Por otro, desarrolló una serie de servicios institucionales a través de convenios de integración y vinculación tecnológica con Estaciones Experimentales del Instituto Nacional de Tecnología Agropecuaria (INTA) y Universidades, entre otros.

La consecuencia de las inversiones orientadas a las mejoras de calidad y provisión tecnológica y la retracción del mercado lácteo por esos años, fue el elevado endeudamiento financiero asumido por la organización. A partir de 2004 la situación se agravó. SanCortenía para el 2005 una deuda de 167 millones de dólares.

Hacia finales de ese año, se firmó un preacuerdo comercial con el Grupo Soros (Adecoagro) intentado un "salvataje" financiero. El preacuerdo sostenía que Adecoagro controlaría el $62,5 \%$ de las acciones de la cooperativa, transformándola en una Sociedad Anónima, a cambio de 120 millones de dólares que se requerían para enfrentar la deuda más urgente. Esto puso a las cooperativas asociadas en una situación contradictoria. Para muchos esa posibilidad de "salvataje" de la empresa resultaba positiva, mientras que otros la repudiaban fervientemente defendiendo los principios cooperativos que le dieron origen.

La situación se modificó tiempo después, en diciembre de 2006, cuando se dio a conocer que la recuperación de SanCor provendría del gobierno de Venezuela, que a través del Banco de Desarrollo Económico Social entregaría 80 millones de dólares a cambio de la provisión de leche en polvo y mejoramiento tecnológico. Con esta nueva opción, SanCor continuó siendo una cooperativa controlada por socios argentinos ( $\mathrm{La}$ Nación, 12.12.06). El acuerdo, por el contrario de lo negociado con Adecoagro, sería un traspaso financiero y no de acciones, acción que no necesita aprobarse por el Consejo de Administración de la Cooperativa.

Este proceso dejó su marca en la morfología institucional. A partir del año 2005, a través de una reforma del estatuto, SanCor pasó a una situación híbrida o de transición entre una cooperativa de segundo grado y una de primer grado, puesto que sus asociados pueden ser socios directos (preferentemente) como cooperativas ${ }^{3}$. En este último caso -cooperativas - debieron ser vaciadas de sus productores asociados y reorientadas en sus funciones -logísticas, transporte, etc.- a

\footnotetext{
3 El primer antecedente sobre su reconversión estatutaria data de una auditoría realizada en 1987 por el Rabobank. Los asociados se mostraron reticentes a aceptar los resultados que indicaban que no existía en el mundo cooperativas de segundo grado en el sector lácteo, dado que la actividad y el producto requerían de una organización directa y controlada.
}

actividades ajenas al acopio e intermediación de leche entre los productores y SanCor. En ese momento se integró con 61 cooperativas, 1.517 tambos y 799 productores asociados directos (Ressel y Silva, 2008).

En la actualidad, la conjunción de un mercado interno recesivo, la pérdida de producción por inundaciones y la caída de exportaciones a Venezuela, Ilevaron a la cooperativa a una nueva situación crítica que de algún modo la retrotraen al escenario de 2004-2005. A estos aspectos coyunturales debemos sumarle algunos estructurales y de larga data propios de la empresa y otros del sector lácteo a nivel industrial. Algunas fuentes destacaron la situación de los niveles de sueldos de directivos, empleados y beneficios para el gremio (ATILRA) que no eran acordes a la situación económica financiera de la cooperativa, aunque los representantes gremiales sostuvieron que el costo laboral representaba solo un $11 \%$ del total, contra un $55 \%$ de la compra de leche a la producción (La Nación, 17.03.17).

Rodríguez, Seain y Rodríguez (Página 12, 01.10.17) sostienen que la crisis de SanCor se produce en un escenario de fuertes dificultades para el sector lácteo argentino en general. La política macroeconómica implementada a partir del 10 de diciembre de 2015 trajo como resultado un desplome del $12,5 \%$ de la producción láctea primaria y una caída del 9,2\% del consumo per cápita en leches fluidas en el transcurso del 2016 en comparación con el año anterior. La caída de la demanda por pérdida del poder adquisitivo de vastos sectores de la población y el fuerte encarecimiento del precio del maíz (principal insumo de la producción de leche) resultaron perjudiciales para el sector en general y para SanCoren particular.

Consecuencia de esta situación, el cierre de tambos se aceleró en el último año y medio alcanzando a un ritmo comparable con el de la crisis de fines de los años noventa y principios de este siglo.

A fines de 2016 SanCorhabía remitido un comunicado a la Comisión Nacional de Valores explicando que la difícil situación de la lechería afectó la capacidad productiva y desempeño económico y se comprometía a la búsqueda de resoluciones adoptadas para dar una solución definitiva a su crisis (Infobae, 06.02.17). El balance anual cerrado en junio de 2016 presentó pérdidas por $\$ 2.421$ millones, con un crecimiento exponencial respecto de los quebrantos de $\$ 447$ millones en 2015, y \$263 millones en 2014. En este contexto, vendió en 2016 su línea comercial de postres, flanes y yogures al Grupo Vicentín por 100 millones de dólares

El déficit volvió a incrementarse en el ejercicio 2017, alcanzando un resultado negativo de $\$ 2.749$ millones, acrecentando la importante deuda con proveedores, mayoritariamente tamberos, a quienes propone acuerdos de quita de hasta el $60 \%$ de lo adeudado, así como con los organismos de recaudación fiscal y previsionales -AFIP y ANSES- (El Cronista, 28.03.18).

Con el fin de superar la crisis financiera que afronta, desde agosto de 2017, el consejo directivo de SanCor buscó llegar a un acuerdo con la empresa neozelandesa Fonterra, la mayor cooperativa láctea y exportadora del rubro a nivel mundial ${ }^{4}$.

\footnotetext{
4 En el año 2002 existió la posibilidad de una asociación de SanCor con otro grupo cooperativo. En un contexto de crisis nacional, se analizó la posibilidad de una fusión
} 
La unión entre SanCory Fonterra daría origen a una sociedad participada en un 30\% por la compañía local que no perdería su condición de unión de tamberos y seguiría al frente de los complejos industriales que hoy administra a lo largo del país. Las riendas del negocio quedarían en manos de la cooperativa de Nueva Zelanda que ofrecía realizar un aporte de capital que según algunas fuentes periodísticas estaría en el orden de los u\$s700 millones y otras en la mitad de esa cifra, con el objeto de disminuir el rojo financiero de la firma (La Razón, 29.11.17; El Cronista, 28.03.18).

Entre las exigencias que SanCor debía cumplir antes de concretarse el acuerdo era ordenar la situación de su deuda. Con este fin SanCor presentó ante los tribunales un Acuerdo Preventivo Extrajudicial (APE) con 2100 acreedores, entre productores y proveedores. El APE sirve para que deudores y acreedores convengan un plan de pagos y busquen su homologación en la Justicia. Para hacerse efectivo requiere contar con la aprobación de al menos la mitad más uno de los acreedores y que representen dos tercios del valor de la deuda. La propuesta consistía en reconocer las deudas totales de aquellos tamberos cuyas acreencias no superaran los $\$ 150.000$, y una quita entre el $40 \%$ y el $60 \%$ para los casos de montos mayores. Unos 1900 acreedores, con un crédito a su favor por $\$ 1500$ millones, acompañaron el APE con notas de conformidad. Esos acreedores representan más del 75\% del pasivo comercial de la cooperativa (La Nación, 05.03.18). La propuesta finalmente fue aceptada el 6 de abril de 2018 en una Asamblea extraordinaria de socios, (Página 12, 08.04.12).

Quedaban pendientes las negociaciones con otros acreedores, como bancos y la Agencia Federal de Ingresos Públicos (AFIP). A esta última la cooperativa le debería alrededor de $\$$ 1.000 millones. Distintas fuentes señalan que la deuda total de la empresa con los diversos acreedores superaba en 2017 los $\$ 5.000$ millones. No obstante, existían versiones de que este sistema de pago tiene el apoyo de los principales acreedores privilegiados, esto es el gobierno nacional a través del Fondo para el Desarrollo Económico Argentino (Fondear), que en 2017 había aportado $\$ 450$ millones y en 2016 otros $\$ 250$ millones, y el fondo de inversión BAF (La Nación, 05.03.18).

Paralelamente, con el fin de obtener fondos frescos, en enero de 2018 SanCor vendió el 50\% de las acciones de la planta Afisa que tenía en la localidad Porteña de la provincia de Córdoba por US\$ 35 millones a sus socios en la misma, el grupo sueco danés Arla foods. Esta empresa fue creada en el año 2000 para producir proteínas a partir del suero de queso para su comercialización en la Argentina y los mercados internacionales.

Además, decidió enajenar cuatro plantas que se mantenían paralizadas: al grupo español Alaisa la planta de quesos de Brinkmann y a la Cooperativa Láctea Huanchilla la de Coronel Moldes, ambas en la provincia de Córdoba, mientras

con Milkaut (perteneciente a la Asociación Unión Tamberos Coop. Ltda) también de la provincia de Santa Fe, que en el caso de concretarse hubiese dado origen a la mayor empresa láctea de la Argentina. El obstáculo principal que no pudo superarse fue la reticencia de la Corporación Financiera Internacional (CFI), brazo financiero del Banco Mundial (BM) para el sector privado, a aportar un financiamiento por $211 \mathrm{mi}$ llones de dólares para la reestructuración necesaria de las dos empresas con el fin de concretar la unión (La Nación, 11/04/02). Véase también Nota 5. que el establecimiento de la localidad de Centeno, provincia de Santa Fe, dedicado a la producción de quesos frescos, fue entregado a la empresa La Tarantela en un acuerdo que contempla el pasaje de activos, como máquinas e infraestructura, y el mantenimiento del personal, mientras que la venta del establecimiento de Charlone, provincia de Buenos Aires, aún no se ha realizado ( $E$ / Cronista, 28.03.18)

No obstante, a principios de diciembre de 2017, cuando todo parecía encaminado a un acuerdo, Fonterra estableció una serie de exigencias que trabaron las negociaciones. La firma neozelandesa evaluó que no era posible una recuperación rápida de la cooperativa sin una reducción del número de personal a la mitad y la inclusión de la línea de flanes, yogures y postres que se había vendido al Grupo Vicentín en 2016 (Chacra, 05.12.17). Ambos aspectos, resultaban difícil de resolver porque Vicentín no está dispuesto a ceder los activos adquiridos el año anterior y por la conflictividad social que implica el despido de 2.500 personas en el contexto actual. De hecho, el visto bueno de la comunidad política, gremial y ciudadana en general en relación al acuerdo se sostenía por la posibilidad de preservar los puestos de trabajo. A ello se agregó una coyuntura en la que Fonterra también tuvo un balance negativo en su último ejercicio equivalente a 348 millones de dólares y una renuncia de su CEO, Theo Spierings (Página 12, 07.04.18) que terminaron por hacer caer la propuesta de solución entre cooperativas.

Teniendo en cuenta estos aspectos, la actualidad de esta cooperativa plantea un escenario crítico donde se busca una solución definitiva. Esta no sería bajo forma cooperativa a partir de una nueva propuesta que surgió de la empresa de capitales nacionales Adecoagro. Todo indica que la solución buscada se encamina a la enajenación de los activos y pasivos cooperativos al sector empresario. De acuerdo a noticias periodísticas, el 12 de abril de 2018 en la sede central de SanCor en la localidad de Sunchales se realizó una asamblea extraordinaria que aprobó por unanimidad las condiciones de asociación e inversión con Adecoagro, que contempla la constitución de una sociedad anónima (Sancor Industrias Lácteas SA) a la que se transfieren las plantas productivas, personal, cargos logísticos, marcas y demás activos y pasivos de la cooperativa. Adecoagro controlará al menos el $90 \%$ de las acciones de la nueva sociedad. El plan de inversiones de Adecoagro consiste en un desembolso de 100 millones de dólares y proveer de leche fluida como pago por la adquisición de diez plantas industriales, dos centros logísticos de distribución, las principales marcas comerciales y mantener los puestos de trabajo de 2.800 empleados, además de hacerse cargo de la deuda hasta 300 millones de dólares que incluye las deudas con AFIP, organismos públicos y acreedores financieros, las que garantizaría con hipotecas sobre las plantas industriales. Por su parte la cooperativa SanCor continuará su actividad productiva como cooperativa de productores de leche, gestionando la materia prima producida por sus asociados y promoviendo el desarrollo lechero a través de asistencia técnica y la prestación de servicios, (El Cronista, 28.03.18; Página 12, 07.04.18; La Nación, 12.04.18).

La empresa Adecoagro tiene antecedentes importantes en el sector lácteo, con 7.000 vacas en ordeña y un mega tam- 
bo de alta productividad (36,7 litros/vaca) en la localidad de Christophersen en el sur de la provincia de Santa Fe, con una capacidad de producción de 250.000 litros diarios, que en 2017 se expresaron en 93,2 millones de litros de leche y una ganancia de 11,2 millones de dólares. Además, la empresa emplea a unas 8.000 personas, sus negocios se extiende a la producción de azúcar, etanol, bioelectricidad, cereales y oleaginosas, en unas 435.000 has bajo su administración en Argentina, Brasil y Uruguay. Desde 2011, Adecoagro cotiza en la Bolsa de Nueva York y tiene una facturación aproximada a los 500 millones de dólares anuales (El Cronista, 26.03.18).

\subsection{Las consecuencias en la cadena láctea}

En 1999 se producían en el país 600 millones de litros de leche más que en 2017, lo que habla de un deterioro del sector durante las últimas dos décadas. La crisis de SanCor viene de varios años, pero su crisis final se enmarca en un contexto donde el sector lácteo tuvo una caída de las ventas de 7,6\% interanual (abril de 2017 vs. abril de 2016) y el cierre 460 tambos durante 2016 según datos del Observatorio de la Cadena Láctea (OCLA). Además, el consumo de leche en la Argentina cayó 4 litros per cápita interanual, hasta ubicarse en 23,12 litros. Dentro de la menor demanda interna, la leche en polvo fue la que registró la caída más fuerte, con 43,8\% interanual; seguida por la manteca, con $13,1 \%$; el yogur, con $9,8 \%$, y la leche líquida, con 9,3\%, (La Nación, 21.06.17).

En este contexto la venta de leche que los productores realizaban a SanCor cayó de 1,5 millón de litros diarios en marzo de 2017 a 950.000 litros en mayo para tener una leve recuperación y estabilizarse en junio en 1,1 millón de litros diarios. Los casi 500.000 litros (30\%) que dejó de captar se repartieron entre muchos competidores, algunos grandes (La Serenísima, Molfino, Ilolay, Danone, Saputo y Verónica) pero principalmente pequeños y medianos procesadores locales (Tregar, Elcor, Milkaut, Yatasto, La Lácteo, Corlasa, Punta de Agua), reduciendo los niveles de concentración que se observa en otros países.

Algunos productores sostienen que el desvío de las entregas de leche que antes hacían a SanCor hacia pequeñas y medianas empresas locales se debe a la mayor eficiencia de muchas de ellas y al hecho de que la gran industria se cartelizó para establecer un precio al productor de $\$ 5,11$ el litro, mientras que las pequeñas empresas pagan hasta $\$ 5,60$.

Por otra parte, la retracción de SanCorha afectado diferencialmente los productos que se comercializan en la cadena de valor láctea. El mayor impacto se registraba en la disminución de leche larga vida dado que SanCor producía 13 millones de litros por mes, crema líquida y manteca, situación que requirió la importación de 200 toneladas de este último producto desde Uruguay, mientras que su posición en quesos si bien importante no era dominante, y en yogures y flanes había enajenado su línea al Grupo Vicentín.
En cuanto a los mercados, el sector externo fue uno de los más afectados con la baja de muchos negocios de leche en polvo. También se resintió algo la comercialización de leche fluida, entre otras líneas de productos (La Nación, 21.06.17).

\subsection{El impacto social en las localidades del interior}

Directores de SanCor, encabezados por su presidente, Gustavo Ferrero, se reunieron el 21 de marzo de 2017 con unos 70 productores tamberos en la localidad de La Carlota, provincia de Córdoba, en el que plantearon su plan de reestructuración que incluye el despido de alrededor del $25 \%$ de su planta total de 4.000 trabajadores, la venta de la cooperativa y la renegociación de las deudas con proveedores. A ello se agrega una reducción de puestos de trabajos indirectos no contabilizados por la disminución de áreas de logística y distribución tercerizadas.

La demora en los pagos a los tamberos generó una crisis de confianza que se expresó durante el último año en la pérdida de 247 productores socios y la disminución de entre un 30 y un $50 \%$ de la leche que entregaban. Con hasta dos liquidaciones impagas, muchos de estos establecimientos no pudieron sostenerse y debieron rematar sus establecimientos y planteles de vacas (La Nación, 23.03.17; 21.06.17).

En el contexto de una crisis del sector los tamberos disconformes se hicieron escuchar. Algunos afirman que desde hace un tiempo muchas cooperativas dejaron de pertenecer al sistema de SanCor. "Para nosotros esa deuda va a quedar impaga y desde el punto de vista comercial lo vamos a tener muy en cuenta en el futuro, cuando nos vengan a pedir que les vendamos leche, afirmó Peluffo". Por su parte Juan José Ubize, productor del oeste bonaerense que entregaba históricamente su leche a SanCor, dice que lo único bueno de esta crisis es que están apareciendo pequeñas y medianas empresas locales o regionales en su reemplazo que son más eficientes y pagan un mejor precio al productor (La Nación, 21.06.17).

Ubize sostiene que "el convenio corresponde al pago de deudas de febrero del año pasado para los productores y de marzo del mismo año para las cooperativas. 'Licuaron los pasivos en forma encubierta'. Matías Peluffo, otro de los productores de leche que no firmaron y están dentro de un grupo de tamberos a los que les quedó un saldo importante con la cooperativa láctea, explicó: "Nos ofrecen solo un $43 \%$ de lo que nos deben. La deuda es de marzo del año pasado, por lo que si ajustara por inflación lo que me ofrecen sería solamente el $33 \%$ del valor real de la deuda original", (La Nación, 29.01.18).

No obstante, la preocupación de los productores trasciende la coyuntura y plantean el interrogante de un mercado sin la presencia testigo de una institución que los represente: "Financieramente, esta crisis de SanCor nos ha complicado muchísimo, sobre todo por dejar de tener fecha cierta de pago. Me preocupa una lechería sin ninguna empresa que sea de los 
productores, como ocurría con SanCor, que históricamente fue muy beneficiosa para los tamberos", (La Nación, 21.06.17).

En un sentido similar puede interpretarse la opinión de Patricio Watson, productor agropecuario y ocasional columnista del diario La Nación, que reproducimos en forma extensa a continuación, dado que describe en una breve síntesis el proceso histórico de instalación, crecimiento y ocaso de la cooperativa láctea y su impacto en muchas localidades del interior, alumbrando tanto los aspectos positivos como negativos en el desarrollo local, y la incertidumbre generada por el vacío institucional ante su desaparición:

"Sancor llegó a nuestra zona, el sudeste de Córdoba en los años 60. Yo estaba en la secundaria y, como ahora, muchas cosas no entendía, pero ver los camiones plancheros -así se llamaba a los que recorrían la zona levantando los tarros lecheros-, pintados con los logos de Sancor nos parecía un paso a la modernidad, ya que venían a retirar la producción diaria a domicilio con lo que se ahorraba el trabajo de llevarla en carros todos los días hasta la fábrica local.

Fue un largo y triste proceso para todos los que vivíamos en las zonas que de a poco iba colonizando esta empresa en su cada vez mayor necesidad de leche para elaborar en sus gigantescas fábricas.

Como ya se habrán dado cuenta, esta historia está contada desde el lado perdedor y nada tiene que ver con la que se cuenta del otro lado, que en pocos renglones puede enumerar los hitos que hicieron tan grande a esta exitosa iniciativa de varias cooperativas de la zona este de Córdoba y oeste de Santa Fe.

En 1940 comenzó a funcionar su primera fábrica de manteca en Sunchales y de ahí en más no paró de crecer. En 1943, manteca para exportar y dulce leche, en 1962 leche pasteurizada, en el 70 yogures y postres, en 1986 crean Sancor do Brasil, en 2002 se asocia con ARLA -una de las mayores cooperativas de Suecia y Dinamarca para deshidratar y concentrar suero-, en 2005 se convierte en cooperativa de primer y segundo grado. En 2008 comienza a ratear y debe reestructurar su deuda. Luego sigue en su camino de crecimiento por medio de alianzas, pero ya con una herida que no cicatrizó totalmente, hasta hoy que presenta un estado financiero cercano a la quiebra.

La otra cara de esta moneda es que Sancor en su brutal expansión llegó a captar producción en cuencas lecheras que contaban con pequeñas industrias y, en poco tiempo, las hizo desaparecer de dos maneras en general. La primera, dejándolas sin materia prima, y la segunda era comprar la fábrica y vaciar la maquinaria para que nunca más se ponga en marcha.

Es muy fácil culpar a la pobre soja de haber expulsado a los tambos cuando en realidad mucha culpa es de estas empresas, pues al llevarse la producción sin elaborar logran empobrecer la zona que pierde puestos de trabajo. Luego, al no tener competencia local pagan precios que no son rentables para los tamberos y cambian de explotación.

Por el contrario, las zonas en que toda esta leche se concentra, florece por los requerimientos de mano de obra y el movimiento económico que significa una gran fábrica. El proceso no se diferencia en nada al de todas las empresas que se expanden por la eficiencia de la escala, y no opino si está bien o mal. Solamente trato de entender por qué algunas zonas se enriquecen y otras se empobrecen.

El resultado hoy es que la mayoría de las cuencas muestran infinidad de taperas donde funcionaban las fábricas locales. Digo la mayoría porque hubo algunos lugares en que los productores advirtiendo esta jugada se juntaron para dar varios pasos adelante en la elaboración de productos lácteos y llegaron a las góndolas.

Que hoy esta empresa esté herida es muy preocupante. De ella dependen muchísimas familias y es el pilar económico de una región cuyos chacareros lograron concretar un sueño de grandeza juntando voluntades bajo el sistema cooperativo. Setenta cinco años después se puede ver que algo se hizo mal a pesar de las ventajas del sistema.

No me gustaría nada que al final se cumpla lo que un amigo norteamericano me dijo una vez en una reunión: 'el sistema cooperativo es buenísimo, pero su defecto es que al ser de todos no es de nadie y puedo anticiparte lo que va pasar en los pueblos que funcionan, en principio todos contentos porque los precios bajan, luego comienzan a fundirse los negocios particulares, una vez solos, todo se encarece y por último la cooperativa crece tanto que se torna difícil de manejar y termina fundida'. Espero que éste no sea el caso y encuentren la manera de salir de esta difícil situación" (La Nación, 24.06.16).

Pocos días después de la reunión en La Carlota donde los directivos hicieron conocer el plan de restructuración a tamberos, los 56 empleados de SanCor de la planta de Coronel Moldes en provincia de Córdoba, se movilizaron, acompañados por vecinos de la localidad, para pedir que la empresa no cierre, luego de agotarse las vacaciones forzadas por 15 días impuestas, cobrar el $40 \%$ de sus sueldos de febrero y tener adeudados parte de sus haberes de enero (La Nación, 23.03.17).

El delegado de los trabajadores movilizados manifestó que la protesta se extendía a otras localidades en situaciones similares: "En todos los pueblos quieren mantener las plantas abiertas; los tamberos, los productores y los operarios confiamos en la gente de SanCor, pero necesitamos información". Señaló que Coronel Moldes -donde se fabrican quesos duros- puede encarar otro tipo de producciones, ya que "tiene tecnología y autorizaciones del Senasa para exportar". Hoy los depósitos de la firma están completos por el stock acumulado. También dejó claro los efectos en cadena que producía esta situación en pequeñas localidades donde la cooperativa era la principal fuente de trabajo afectando toda la cadena de pequeños negocios y servicios: “Esta movilización también es para explicarle al resto del pueblo que si no pagamos es porque a nosotros no nos acreditan nuestros sueldos. Queremos salvar el trabajo y la producción" (La Nación, 28.03.17).

Las instalaciones de SanCor en la localidad de Brinkman también se encuentran sin actividad, con sus 120 operarios de vacaciones. Allí se recibe leche y es un depósito de productos para la distribución. También se encuentran sin actividad las plantas de Centeno (Santa Fe, 70 empleados) y Charlone (Bue- 
nos Aires, 51 empleados). En cuanto a esta última, en el partido bonaerense de General Villegas, el presidente de la Comisión de Agricultura de la Cámara de Diputados de la Nación, Gilberto Alegre (Frente Renovador), patrocinó un recurso de amparo de los trabajadores para que no se cierre esa planta (La Nación, 28.03.17). Una situación crítica que se extendía territorialmente y que llevó al gremio ATILRA a convocar a un paro nacional por 24 horas (La Nación, 04.05.17). A ello se sumó un programa de retiros voluntarios en la sede central en la localidad de Sunchales, que redujo el plantel de 320 a 225 personas, la no renovación de contratos y una disminución de los salarios en un 15\% (La Nación, 12.04.18).

La crisis convocó la atención de intendencias, legislaturas locales, gobiernos provinciales y gobierno nacional en la búsqueda de apoyo financiero y negociaciones para resolver la compleja situación. El Secretario de Lechería de la provincia de Santa Fe, Pedro Morini, sostuvo que "...tras 60 días de negociaciones no se llegó a nada; yo soy pesimista en torno a la llegada de fondos. Además, el daño es irreversible (para la empresa): los tamberos que se fueron no van a volver y el mercado que se pierde va a ser difícil de recuperar [...] La gente estás desesperada; lleva 60 días sin cobrar y sin saber que va a pasar. Lamentablemente los platos rotos los está pagando Sancor. El acuerdo con el propio gremio podría hacerse a futuro si la intención fuese resolver el conflicto. Quieren solucionar todo el problema de la lechería de un solo plumazo y en el medio queda la cooperativa" (La Nación, 04.05.17).

Por su parte, el gobierno nacional, luego de sucesivos apoyos financieros en 2016 y 2017, advirtió en palabras del Presidente de la Nación que la solución en el conflicto "...requiere que se reviertan muchos errores cometidos en los últimos 10 años.., entre los que mencionó "...un pésimo convenio laboral casi inviable para la industria..." (La Nación, 03.05.17).

\subsection{Organización y capital social}

Como se ha descrito, desde sus orígenes SanCor fue una cooperativa de segundo grado, es decir, una cooperativa de cooperativas. Sin embargo, esta situación se modificó a partir de la reforma de su estatuto en 2005 para reconstituirse en una organización de primer grado.

Con esta transformación estatutaria, se introdujeron algunas modificaciones que permitieron reproducir vínculos al modo de una cooperativa de primer grado, en determinados casos con una relación directa con sus productores asociados. Las cooperativas que inicialmente conformaron la organización pasaron a ser prestadoras de servicios (inseminación, seguros, transporte, etc.), pero dejaron de intermediar en la relación comercial y técnico-productiva entre SanCor y los socios directos.

Esta modificación dio como resultado un sistema que podríamos caracterizar como "mixto". En este sistema, no todos los productores se integran directamente a SanCor y las coo- perativas aún pueden ser socias, como puede verse en el listado de opciones que plantea la entidad a sus asociados en esta nueva etapa:

a) Cooperativas del sistema tradicional: sus asociados aún no han optado por la asociación directa.

b) Cooperativas del sistema tradicional con entregas parciales de producción: solo en algunos casos los productores se han asociado en forma directamente.

c) Cooperativas en liquidación directa: continúan con entrega directa en tambos.

d) Cooperativas en liquidación directa con entregas parciales de producción: cooperativas que continúan entregando a tambos directamente, con algunos socios directos.

e) Cooperativas originarias sin entrega de leche: la totalidad de sus miembros se asociaron a SanCor.

f) Productores asociados provenientes de cooperativas asociadas: productores asociados que integran los tipos b) y d).

g) Otros productores: productores que provienen de cooperativas que han formado parte de SanCor.

Esta situación supone, independientemente del tipo de cooperativa, que SanCorestablece una relación directa del socio con la organización y, a la vez, mantiene algún tipo de relación con las cooperativas que permanezcan asociadas, pero estas cumplen otra función. Esto por un lado permite observar una representación más explícita en cuanto a la identificación del productor-socio, su compromiso directo y pertenencia en SanCor, pero por otro lado complejiza la organización institucional porque modifica el carácter de sus asociados y requiere nuevos modos de negociar las decisiones y acciones a tomar.

Aún con estos matices, SanCor ha ingresado claramente en la categoría de OIM en su variante OICED. De hecho, actúa como un holding de empresas (Lattuada y Renold, 2004), con una gran operatoria comercial que no solo se orienta a la actividad láctea sino también a otros rubros: seguros de retiro, aseguradoras de riesgos de trabajo, insumos, etc. Esto permite observar la existencia de actividades directamente vinculadas a la racionalidad empresarial capitalista tipo. Sin embargo, aquellas vinculadas a la racionalidad de tipo valorativa inspirada en los valores que le dieron origen también son sostenidas por las prácticas y discursos que SanCor promueve. En apariencia observamos una modalidad OIP pero sin embargo las acciones racionales con arreglo a valores se encuentran subordinadas a las arregladas según fines.

En este sentido, es posible distinguir aquí acciones vinculadas a la noción de capital social. En el nivel macro, especialmente en materia de sinergia institucional, SanCor mantiene una relación muy estrecha con instituciones públicas y privadas especialmente vinculadas a la producción y promoción de mejoras tecnológicas orientadas a mejorar la calidad de los productos.

La puesta en el mercado de la línea Bio, por ejemplo, es la resultante de un convenio con el Consejo Nacional de Investigaciones Científicas y Tecnológicas (CONICET). Asimismo, la cooperativa mantiene convenios de este tipo con el INTA y los Ministerios de Agricultura provinciales. 
Existe además una vinculación con otras empresas, en un sentido de red, con el motivo de generar nuevos productos y de mayor calidad. En el año 2000, por ejemplo, se constituyó la Arla Foods Ingredients $S A$, siendo éste un emprendimiento conjunto entre SanCory la cooperativa sueco-danesa Arla Foods para elaborar y comercializar productos para Argentina y el mercado internacional. Las leches enriquecidas desarrolladas especialmente para uso medicinal fueron posibles por un acuerdo con Farmacia Nutricional S.A.

Uno de los ejemplos más relevante de esa sinergia institucional en el plano político nacional e internacional ha sido el acuerdo con el gobierno venezolano para la obtención del financiamiento que posibilitó su continuidad como cooperativa integrada por socios argentinos, pero que llegó a su fin con el cambio de gobierno y la crisis político económica de Venezuela..

En cuanto a la eficiencia organizativa, es a partir de la renovación del Estatuto que la organización de la cooperativa lógicamente se modifica siendo determinante el logro de un nuevo tipo de vinculación para lograr sinergia. En principio, el trato directo con los productores asociados permite una mayor flexibilidad en la toma de decisiones sostenida sobre el vínculo directo asociado-cooperativa, resultando en este sentido muy positiva. Como indican las fuentes entrevistadas, la nueva forma de organización facilita alianzas estratégicas, que contribuyen a la sinergia institucional antes descripta permitiendo instrumentar las lógicas de segundo o primer grado de acuerdo a los beneficios de las acciones a realizar. Esto también altera la relación de los productores con los precios puesto que las cooperativas actuaban como intermediarias en el pago de la materia prima, pudiendo optar por pagar precio completo o retener y destinar márgenes a otras acciones institucionales.

En el nivel micro de la formación de capital social, al considerar la variable integración intracomunitaria, la cuestión se presenta más compleja al tomar en cuenta los atributos que implica una entidad de segundo grado. Por otra parte, la identificación con los principios cooperativos ha quedado, a nuestro criterio, relegada a un plano más bien residual ya que la racionalidad instrumental en cuanto a la obtención de rentabilidad se constituye actualmente como el móvil "cooperativo". No obstante, la reforma de estatutos con la intención de incorporar los socios en forma directa, resulta un avance sustantivo respecto de las posibilidades de una mayor integración intracomunitaria.

Por último, en cuanto a la conexión extracomunitaria la institución ocupa un lugar destacado en la comunidad de origen, y en la identificación de la misma con las distintas instituciones del medio local, siendo la principal expresión territorial de ello la localidad de Sunchales en la provincia de Santa Fe.

Por otra parte, desde el punto de vista de representación de intereses SanCor expresa una situación de tensión o ambivalencia que se traslada a los espacios institucionales de participación, como en CONINAGRO (Confederación Intercooperativa Agropecuaria), única entidad de tercer nivel con representación de las cooperativas agropecuarias en las instancias de negociación de políticas públicas. SanCor tradicionalmente disputó con la Asociación de Cooperativas Argentinas (ACA) la conducción de CONINAGRO, siendo además uno de los soportes económicos más importantes de la misma. No obstante, dados los beneficios de sus vinculaciones con el poder político, facilitador del acuerdo financiero con Venezuela, en pleno conflicto del "campo" con el gobierno de Cristina Fernández a raíz de la frustrada incorporación del sistema de retenciones móviles a las exportaciones, SanCor no dudó en anunciar su retiro de CONINAGRO a fines de 2008. Pero, SanCor tiene además de capacidad propia de representación, otras instancias de participación, ya no en representación de cooperativas de productores tamberos, sino de eslabón muy importante de la cadena de transformación láctea. En este sentido, SanCor participa del Centro de Industria Láctea (CIL), entidad sectorial tradicional representativa de la fase industrial, teniendo allí un gran peso. El CIL es la instancia representante de la industria en los diálogos sectoriales introducidos por el Estado nacional, la Junta Intercooperativa de productores lácteos, las Mesas de Lechería y demás entidades.

Por su peso económico y densidad organizacional, SanCor tiene un rol político que trasciende los lugares que ocupa en las entidades representativas del sector que este caso es de mayor importancia aún pues, esta tradicional empresa láctea argentina ya no tiene un lugar en la institución política por excelencia del sector agroalimentario, CONINAGRO.

SanCor controla o ha tenido participación accionaria en numerosas empresas del sector, como se ha mencionado en páginas anteriores, a las que se agregan en otros sectores de actividad: Asociación Mutual SanCor (servicios de salud, turismo, subsidios especiales); SanCor Medicina Privada SA (salud); Fundación SanCor (capacitación de dirigentes); Federación de Centros Juveniles Agrarios Cooperativistas Zona SanCor (formación de jóvenes); SanCor Cooperativa de Seguros Ltda (Ressel y Silva, 2008).

A partir de esta red institucional se brinda una multiplicidad de servicios a los socios, entre los que cabe destacar la asistencia técnica a productores y cooperativas, y las iniciativas para la formación y la búsqueda de alternativas productivas para los jóvenes, como la llevada adelante con la Fundación Avina de Suiza, o la integración de la Red de Jóvenes Cooperativistas del Cono Sur, entre otras.

En síntesis, como en otros casos, pero en SanCor probablemente con mayor visibilidad, el recorrido de la cooperativa también refleja el de la actividad láctea en el país y la suerte de los sujetos sociales que de ella participan. Esta actividad se ha concentrado en los últimos treinta años en unas pocas usinas y cadenas de la gran distribución, con gran capacidad de presión sobre los precios al consumidor. Asimismo, en el contexto de crisis actual, la cooperativa se ha visto obligada a adaptarse a las necesidades de los modos de producir y los mercados actuales, dejando de lado la introducción de mejoras en los precios pagados a los tamberos y a la calidad de la materia prima obtenida por ellos. El abandono de los principios cooperativos por los criterios empresariales que se observaban como resultado del proceso de reconversión de la década de 1990, toman nuevo impulso en el escenario actual de negociaciones con la venta a Adecoagro que se concreta en abril de 2018. 


\section{A modo de conclusión}

Puede sostenerse que en la Argenina, desde la década de 1970, se asiste a la fase final del Régimen Social de Acumulación de regulación estatal de la economía; tendencia que se profundiza hacia finales de los 80 , dando origen en los 90 a la consolidación de un nuevo Régimen Social de Acumulación basado en la retracción del Estado y la desregulación y apertura de la economía. Una tendencia que llega -a su vez- a su fin con la crisis económica, política e institucional del 2001, y que da paso a una progresiva consolidación de un modelo de sustitución de importaciones, asistencia social y consumo interno con activa intervención estatal en la economía y en la organización social y política de vastos sectores sociales de bajos ingresos y desocupados, hasta la crisis económica y derrota política del gobierno kirchnerista en 2015. Con la presencia de un nuevo gobierno bajo la administración de Mauricio Macri, comienza a modificarse el proceso económico anterior con una impronta liberal dando paso a una menor intervención estatal.

Estos períodos pendulares característicos de la vida político económica de Argentina constituyen contextos económicos, sociales y políticos, diferenciados, cuyas variaciones condicionan las actividades de las cooperativas y las tensiones y transformaciones de sus formas organizativas.

Como es sabido, las acciones de estas organizaciones de primer y segundo grado, en cuanto a su estructura organizacional no operan en el vacío, sino en contextos económicos, sociales y políticos que contribuyen a moldearlas, tanto en los roles de quienes las componen como en los aspectos que hacen a la dimensión normativa vinculadas a los valores, los objetivos económicos y empresariales, sus discursos y las acciones implementadas para alcanzarlos.

Hemos visto, en todos los casos, procesos de mutación en los principios cooperativos, no de su anulación absoluta pero sí de su tensión, complementación o, en todo caso, su paso a un "segundo lugar" frente a la lógica empresarial, racional instrumental en términos weberianos, que sostienen las organizaciones cooperativas como organizaciones puramente económicas.

De este modo, es evidente que la idea de "asociarse" que prevalece no implica necesariamente acciones cooperativas en el sentido tradicional, aun cuando es posible encontrar acciones vinculadas a la producción de capital social del modo en el que hemos tratado de analizarlo.

A partir del 2016 la modalidad de la relación Estado-Mercado vuelve a pendular en sentido contrario al período 20012015 acentuándose ahora el segundo término de la relación. Características similares al proceso anterior a 2001 parecen ir instalándose. De ser así, las formas OIM (OICED) volverán a ser acentuadas en detrimento de las formas OIM (OM) y por supuesto las tradicionales OIP redoblarán su esfuerzo por adecuarse a la nueva modalidad. El caso complejo de la transformación de una cooperativa líder como Sancor (OICED) en la
Provincia de Santa Fe (Argentina) en una Sociedad Anónima -cierto que por una profunda crisis económico-financierada cuenta de la profundización en la modalidad OICED y su paso a una sociedad empresarial. Justo es considerar que estos saltos (en Sancor) de cooperativa de segundo grado a cooperativa de primer grado y luego a organización empresarial indican una dramática flexibilidad operativa y adaptativa tanto respecto de la resolución de sus problemas organizacionales e institucionales internos como a los ciclos pendulares de la política económico-social de los gobiernos nacionales referidos al sector.

SanCor ejemplifica una metamorfosis del modo cooperativo al modo gerencial que se expresa en otros tipos organizacionales con distintos matices. El caso de SanCor es quizá el más heterogéneo en términos morfológicos pues se presenta como transicional a partir del tipo y los modos de vinculación con los asociados -sean productores o cooperativas-. En este sentido, el cooperativismo es un ethos y una práctica gestionada desde los inicios de la organización, de hecho, su base de creación. Las transformaciones en el mercado lácteo, nacional e internacional, así como también de la demanda y calidad han contribuido a esta adaptación más lenta pero constante a los modos capitalistas puros de reproducción del capital prevaleciendo algunas acciones que permiten un contacto más directo hacia fuera de la cooperativa.

Aún con la diversidad económica, territorial y organizacional, el cooperativismo agrario en la Argentina, ha sabido generar en sus inicios un alto grado de identificación de los socios con el proyecto cooperativo, así como instalarse en destacado referente ideológico y simbólico de las comunidades del interior donde se asienta. Claramente los modelos OIC son favorables a esta integración, generando una red de confianza e identificación con la institución, mientras la misma se hace más laxa en la medida que las cooperativas transitan hacia modelos paradojales (OIP) y/o empresariales (OICED). No obstante, aún en estos casos de mayor distanciamiento asociadocooperativa, en ciertos casos las vinculaciones contractuales pasan a desplazar y reemplazar las condiciones de seguridad y compromiso que anteriormente se obtenían por el reducido número de integrantes, la relación face to face cotidiana, y una mayor identificación ideológica. En otros, la creación de fundaciones o áreas destinadas a la generación de numerosas actividades con los asociados y con jóvenes y mujeres de su grupo familiar, o la realización de un Balance Socialjunto a la comunidad en la que se encuentran insertas, intentan reconstruir los lazos debilitados por una mayor alteridad burocrática de la organización ${ }^{5}$.

El crecimiento económico de las cooperativas, la expansión en volumen y complejidad de sus negocios, y sus transformaciones organizacionales, tienden a debilitar los lazos intracomunitarios, sin embargo, suelen favorecer la conexión extracomunidad, al requerir una integración a estructuras de segundo grado, generar alianzas estratégicas con otras empresas para diversificar sus actividades y servicios o ganar nuevos mercados. De este modo se abre a sus asociados un abanico

\footnotetext{
${ }^{5}$ Véase como un ejemplo en este sentido el excelente análisis que Graciela Mateo (2011) realiza de la Cooperativa Arrocera Villa Elisa de Entre Ríos, Argentina.
} 
de interrelaciones técnicas, de información, de capacitación, financiamiento y desarrollo que trasciende el contexto de la organización y la propia comunidad. También es reconocida la participación de las cooperativas y sus asociados en las iniciativas de desarrollo rural, así como las actividades vinculadas a la capacitación técnica en grupos vinculados a las organizaciones de segundo grado o federaciones y de promoción cultural y gremial.

El cooperativismo por otra parte, en su un nivel macro, expresa un alto grado de sinergia institucional, con las entidades privadas locales -escuelas, entidades financieras, cooperativas de servicios locales-y públicas, a partir de los mecanismos de regulación en los que se encuentra enmarcados -leyes y resoluciones-; sus vinculaciones con los gobiernos locales y municipales; y las de sus federaciones y confederaciones con los gobiernos provinciales y nacional.

La participación en planes estratégicos sectoriales, o los compromisos asumidos en la ejecución de políticas de calidad o certificaciones de origen de incipiente desarrollo, son solo algunos ejemplos de las experiencias existentes. A ello se agrega su estrecha vinculación y cooperación con universidades nacionales y organismos de ciencia tecnología, ya sea formando parte de sus organismos de conducción regionales o nacionales como en el caso de INTA, o en el desarrollo de insumos y productos para el sector, con INTA, universidades o el CONICET entre otros.

Finalmente, en cuanto a su eficiencia organizativa, las cooperativas suelen tener diversos grados de eficiencia en la prestación de servicios a sus socios, rindiendo cuentas en sus asambleas y consejos directivos. El crecimiento en escala y los cambios en la morfología institucional consecuente suelen estar acompañados de un aumento de la eficiencia en los servicios prestados.

El crecimiento de algunas de ellas ubicándose como actores económicos de primer nivel en las cadenas de valor agroindustriales -caso lácteos, vitivinicultura, y granos por ejemplodan cuenta de esa eficiencia en las actividades principales que definen su misión. A ello se agrega el reconocimiento como referente e interlocutor válido y confiable por otros actores sociales públicos y privados, en cuestiones comerciales, sanitarias, y tecnológicas, especialmente a aquellas cooperativas de mayor importancia económica y organizacional, así como las federaciones o asociaciones de segundo grado. No obstante durante la década de 1990, las condiciones de apertura y desregulación de la economía, convertibilidad monetaria y retracción del Estado, contribuyeron a una crisis del sector de pequeños y medianos productores agropecuarios que, como mencionamos, constituyen el grueso de los asociados de las cooperativas.

En síntesis, el cooperativismo agrario en la Argentina, aún con el grado de heterogeneidad existente en el plano económico y organizacional, se constituye en una de las formas asociativas del medio rural con un capital social significativo para cumplir un relevante papel como agente de desarrollo local y regional al expresar: a) un elevado nivel de integración comunitaria; b) una fluida conexión extracomunitaria; c) un reconocimiento interno y externo de su nivel de sinergia institucional; y d) un aceptable grado de eficiencia organizativa.
No obstante, todo ello puede ser válido en la medida que el cooperativismo no pierda la esencia de su naturaleza manteniendo como columna vertebral de su organización "los valores", porque el "arreglo a fines" en contextos históricos disruptivos como los vividos en Argentina y sectores altamente concentrados como el lácteo, terminan dejando a estas organizaciones a la suerte de cualquier empresa, su eficacia en el mercado. Y allí, todo lo construido en un siglo como agente de desarrollo se evapora. 
Fuentes y Bibliografía

Fuentes

Diarios:

Infobae

El Cronista

La Capital

La Nación

La Razón

Página 12

Gobierno de Santa Fe:

https://www.santafe.gov.ar/ipec (consultado 17.12.18)

http://www.santafe.gov.ar/archivos/estadisticas/Santa_ Fe_en_Cifras.pdf (Consultado 17/01/14).

IPEC (2012), "Censo Nacional de Población, Hogares y Viviendas 2010. Síntesis de los Resultados Definitivos", Gobierno de Santa Fe, diciembre.

IPEC (2013), “Crecimiento poblacional de las localidades en la provincia de Santa Fe", Gobierno de Santa Fe, Santa Fe.

Ministerio de la Producción (2008). Cadena láctea santafesina. Plan Estratégico. Santa Fe, Gobierno de la provincia de Santa Fe, Santa Fe.

Ministerio de Agricultura, Ganadería y Pesca, www.minagri.gob.ar.

Institucionales:

Entrevistas Gerente de SanCor, noviembre 2006

SanCor Cooperativas Unidas Ltdas, Estatuto, 2005

SanCor, www.sancor.com, 2017.

Revistas:

Chacra, 05.12.17

Bibliografía

ANLLÓ, G.; BISANG, R. y SALVATIERRA, G. (eds.) (2010): Cambios estructurales en las actividades agropecuarias. De lo primario a las cadenas globales de valor, Buenos Aires, CAPAL-PROSAP.

BARSKY, O. y FERNÁNDEZ, L. (2008): Cambio Técnico y Transformaciones Sociales en el Agro Extrapampeano, Buenos Aires, Teseo.

BARSKY, O. y GELMAN, J. (2009): Historia del Agro Argentino. Desde la conquista has comienzos del siglo XXI, Buenos Aires, Sudamericana.

BENECKE, D. W. (1973): Cooperación y Desarrollo, Santiago de Chile, Ediciones Nueva Universidad, Universidad Católica de Chile.

BISANG, R.; ANLLÓ, G. y CAMPI, M. (2008): "Una revolución (no) tan silenciosa. Claves para pensar el Agro en Argentina", Desarrollo Económico, 48, pp. 189-190.

FERNÁNDEZ, S.; LATTUADA, M. y RENOLD, J. M. (2004): “El cooperativismo en el complejo lácteo: evolución y estrategias recientes en el caso de la provincia de Santa Fe", en RENOLD, J.M. y LATTUADA, M. (coords), El complejo lácteo en una década de transformaciones estructurales, Buenos Aires, Biblos.

LATTUADA, M. y RENOLD, J. M. (2004): El cooperativismo agrario ante la glo- balización, Buenos Aires, Siglo XXI.

LATTUADA, M.; NOGUEIRA, M. E.; RENOLD, J. M. y URCOLA, M. (2011a): "Mapa de situación del cooperativismo agropecuario argentino 2007", Realidad Económica, 260, pp. 101-122.

LATTUADA, M.; NOGUEIRA, M. E.; RENOLD, J. M. y URCOLAa, M. (2011b): “EI cooperativismo agropecuario argentino en la actualidad. Presentación y análisis de tres casos desde la perspectiva del capital social", Mundo Agrario, 23, segundo semestre.

MATEO, Graciela (2011): “La Cooperativa Arroceros Villa Elisa, un buen ejemplo de la tradición cooperativista de Entre Ríos (Argentina)", Mundo Agrario, vol.11, 22, ene-jun.

MOYANO ESTRADA, E. (2006): "Capital Social y desarrollo en zonas rurales", en MANZANAL, M., NEIMAN, G. y LATTUADA, M. (comps.), Desarrollo rural, organizaciones e instituciones, Buenos Aires, CICCUS.

NOGUEIRA, M. E. (2008): Producción familiar en un régimen social de acumulación excluyente: el caso de tamberos en el departamento Iriondo al sur de Santa Fe (1991-2001), (Tesis de Maestría), Buenos Aires, FLACSO.

NUN, J. (1987): "La teoría política y la tradición democrática", en NUN, J. y PORTANTIERO J.C., Ensayos sobre la transición democrática en Argentina, Buenos Aires, Puntosur.

RENOLD, J. M. (1995): Estructura y Organización cooperativa en el campo argentino. Un análisis antropológico-institucional, Rosario, Magíster.

RESSEL, A. B. y SILVA, N. C. (2008): Proyecto: impactos de la integración regional del MERCOSUR en el sector cooperativo. Estudio de Caso: SanCor Coop. Unidas Limitada, La Plata, Instituto de Estudios Cooperativos, Facultad de Ciencias Económicas, Universidad Nacional de La Plata.

SCHEJTMAN, A. y RAMÍREZ, E. (2004): Desarrollo Territorial Rural. Aspectos destacados de experiencias en América Latina, La Paz, Fondo Mink'a de Chorlaví.

VILLEGAS, R. (1979): "El papel de la empresa cooperativa en el proceso de desarrollo y el problema de la pérdida de participación de los asociados durante su crecimiento", en VV.AA., Cooperativismo y Desarrollo, Buenos Aires, Intercoop.

WEBER, M. (1984): Economía y Sociedad, México, Fondo de Cultura Económica.

WOOLCOCK, M. (1998): "Social capital and economic development: Toward a theoretical synthesis and policy framework", Theory and Society, 27 (2), pp. $151-208$ 